\title{
Herakles Hermelerinin Anlamı ve Kullanımı
}

\author{
The Meaning and Function of the Herms of Heracles
}

\begin{abstract}
Nazlı YILDIRIM*
Özet: Tanrı Hermes ile doğrudan bağlantılı olarak yorumlanan Hermelerin, antikçağda farklı tanrıları betimlemek için de kullanıldığı artık bilinmektedir. Ancak Hermes Hermelerinin sınır taşı ya da mezar işaretçisi olarak kullanıldıkları düşüncesi, Herme biçiminde betimlenen diğer tanrıların, kimlikleri ve özellikleri göz önüne alındığında genelleme yapmaya olanak vermemektedir. Söz konusu bilgiler 1şığında bu çalışma, Herme biçimindeki Herakles betimlemelerinin, kullanım alanları ve anlamları üzerinde yoğunlaşmaktadır. Araştırmada, hem gymnasium gibi sosyal yapılarda hem de steller ya da lahitler gibi mezar sanatı ile doğrudan ilişkili alanlarda karşımıza çıkan Herakles Hermeleri değerlendirilmiş olup, bu örneklerin kullanım amaçları hakkında öne sürülen farklı düşünceler de ele alınarak, Herakles Hermelerinin anlamları bir kez daha sorgulanmıştır.
\end{abstract}

Anahtar Sözcükler: Herakles, Herakles Hermeleri, Hellen Pantheon’unun Koruyucu Tanrıları

Abstract: It is known that herms have been directly interpreted as linked to the God Hermes, but which were in fact used to portray different Gods in addition to Hermes in antiquity. Consequently the idea that the Herms of Hermes were employed as a land or grave marker can not be generalised to all herms when the characteristics and the identities of the other gods that are also described as herms are taken into account. In consequence, this paper focuses on the meanings and the areas of employment of those herms representing Heracles. In this study the Herms of Heracles found in both social structures such as gymnasium, and on grave stelai or sarcophagus directly related to fields such as funerary art are assessed and consideration is taken of the various thoughts that have been put forward concerning the places of use of these examples, and the meanings given to the Herm of Heracles are re-examined. From the result of this reexamination it can be understood that Heracles, as the personalization of physical strength, endurance and heroism, was worshipped as a protective god, preventing evil, punishing breakers of promises and preventing trouble and disasters from happening to people.

Keywords: Heracles, Herm of Heracles, Protective Divinities of the Greek Pantheon

Hermeler, üst kesimi yarım gövde biçiminde yontulmuş, alt kesimi bir sütun gövdesine benzeyen, kökeni Tanrı Hermes'e dayandırılan ve genellikle ithyphallik anlatıma sahip eserlerdir (RE 8-1, 696-708). Bugüne kadar yapılan araştırmalar sonucunda, Hermes Hermelerinin kökeni, anlamları ve kullanım alanları konusunda pek çok farklı görüş bulunmaktadır. En çok üzerinde durulan fikirler, Hermes Hermelerinin sınır taşları ya da mezar işaretçileri olarak kullanıldıklarıdır.

Bazı araştırmacılar, yeraltı ya da palaestra tanrılarını betimlemek için kullanıldıklarını düşünmektedir (Hermeler ile ilgili ana kaynakça olarak: Curtius, 1903; Lullies, 1931; Goldman, 1942; Pfuhl-Möbius, 1977, 46; Wrede, 1985; Willer, 1994).

Hakkında çok fazla araştırma yapılmış olan Hermes Hermelerinin yanı sıra, pilaster şeklindeki

\footnotetext{
* Arş. Gör., Akdeniz Üniversitesi, Edebiyat Fakültesi, Arkeoloji Bölümü, Antalya, nazyildirim@akdeniz.edu.tr
} 
bu formun, antikçağda Hermes dışında başka tanrı ve tanrıçaları betimlemek için de kullanıldığ bilinmektedir (Harrison, 1912, 365; Wrede, 1985, 17-31). Aphrodite ve Pan Hermeleri doğurganlık ve bereketin simgesi olarak (Harrison, 1965, 136, 138-139), Apollon ve Hekate Hermeleri şehir kapıları ve geçitlerin koruyucu tanrıları olarak (Harrison, 1965, 113, 125), Athena Hermeleri ise -kullanımı sinırlı olmakla birlikte- genellikle gymnasium gibi bedensel ve zihinsel aktivitelerin yapıldığı mekanlar için süsleyici bir öğe olarak yorumlanmışlardır (Cicero, I, 4, 3; Harrison 1965, 125). Özellikle Aphrodite, Apollon, Athena, Hekate, Pan ve Herakles, bazı tanrısal özelliklerinden dolayı Herme șeklinde betimlenmişlerdir (Harrison 1912, 365; Wrede, 1985, 17-31). Herme biçiminde betimlenen tanrısal kişiliklerden en dikkat çekeni ise hiç şüphesiz Herakles'tir. Çünkü Herakles doğuştan tanrı değildir; insanlar tarafindan sonradan tanrılaştırılmıştır. Bu bağlamda, yarı tanrı yarı insan olan Herakles'in hangi nedenlerden dolayı Herme biçiminde betimlendiği konusu oldukça önemlidir.

Herakles Hermeleri (Herakles Hermesi ifadesine ilk defa Cicero'nun Atticus'a gönderdiği mektupta rastlanmaktadır. Cicero mektubunda Tusculum'daki villasının gymnasium'u için bir Herme sipariş ettiğinden ve Hermelerin gymnasium'lar için uygun bir sembol olduğundan bahsetmektedir. Cicero, I, 10, 3; 1. 6. 2) üst kısmı Herakles'i betimleyen tipik bir herme biçimindedirler (LIMC IV 1, 781-784; Harrison, 1965, 140; Volster, 1988, 7-34), (Res. 1). Genellikle sakallı ve olgun olarak betimlenen Herakles Hermelerinde, Herakles'in belirteci olan aslan postu, bir himation gibi vücudu sararak kapatmaktadır ancak çıplak örnekler de söz konusudur (Res. 2). Bazı örneklerde ise ellerinde birer bereket boynuzu (LIMC IV 1, 1160, 1165; Ritter 1995, 122-123, pl. 9, Res. 8) ya da Herakles'in belirteci olan bir sopa taşıdıkları görülür (LIMC IV 1, 1109, 1148, 1165, 1166, 1168; Harrison, 1912, 365-367), (Res. 3). Bu ana tiplerin yanı sıra sakalsız ve genç bir figür olarak betimlenen Herakles Hermeleri de bulunmaktadır (LIMC IV 1, 1254-1255; Bammer, 1988, abb. 30), (Res. 4).

Ele geçen örnekler genel olarak değerlendirildiğinde, Herakles Hermelerinin gymnasium ya da palaestra gibi bedensel ve zihinsel eğitimlerin verildiği yapılar içerisinde bağımsız duran heykeller ya da atlet heykellerine destek olarak; mezar steli ve lahit gibi mezar sanatı ile doğrudan bağlantılı eserlerde kabartma figürler olarak; mezar içerisinde, mezar armağanı olarak ya da fibula, yüzük, sikke gibi küçük eserler üzerinde figüratif bir öğe olarak kullanılmış oldukları anlaşılmaktadır (Bağımsız duran Herakles Hermesi örnekleri için bkz.: LIMC IV 1, 1127-1155; Volster, 1988, abb. 1, 2, 14, 15, 17, 19, 20, 21, 23, 25, 31; Kreikenbom, 1990, Taf. 43-44. Pilaster şeklinde düzenlenmiş örnekler için bkz.: LIMC IV 1, 1106, 1111; Volster, 1988, abb. 33-35. Destek şeklinde düzenlenmiş örnekler için bkz.: Mendel, 1908, no. 129; Volster, 1988, abb. 16, 32; Mezar steli örnekleri için bkz.: Pfuhl-Möbius, 1977, no. 141, 143, 161, 256, 646, 730. Lahit örnekleri için bkz.: Koch, 1975, no. 166; Baratte-Metzger, 1985, no. 166.; Rogge, 1995, no. 48. Lahitler üzerinde görülen girland taşıyıcı Hermeler için bkz.: Işık 2007, 96-97. Bronz örnekler için bkz.: LIMC IV 1, 1161-1163. Terrakotta örnekler için bkz.: LIMC IV 1, 1156-1160; Töpperwein, 1976, 130, no. 533; Çakıc1, 2007, 86, Res. 8; Işın, 2007, kat no. 56, res. 61; Marcade, 1969, 454-456, lev. XIX, XX; Küçük eserler üzerinde görülen örnekler için bkz.: LIMC IV 1, 1120-1124; Volster, 1988, abb. 6).

Genel olarak Herakles Hermelerinin İ.Ö. III. yüzyıldan itibaren üretilmeye başlandığı ve kullanımının Roma Dönemi sonlarına kadar devam ettiği; Mısır, Hellas ve Anadolu'nun batı kıyıları da dahil olmak üzere pek çok yerde karşımıza çıkan örnekler nedeniyle bu tipin ve üretiminin belirli bir bölge ya da atölye ile ilgili olmadığ düşünülmektedir (Vorster, 1989, 281282; Işın, 2007, 94). Ancak Herakles Hermeleri ile ilgili en büyük sorun, üretim yerleri ve kökeni değil, kullanım amaçları konusundadır. Bu konuda pek çok farklı görüş bulunmasına rağmen bugüne kadar kesin ve tatmin edici bir bilgi ne yazık ki bulunamamıştır.

Büyük çoğunluğu gymnasium'lardan elde edilmiş yontular ve antik kaynaklar nedeniyle, 
araştırmacılar tarafından kullanımları ile ilgili en çok kabul gören fikir; Herakles Hermelerinin gymnasium ya da palaestra gibi eğitim alanları için birer işaret levhası ya da söz konusu bu sosyal mekanlarda dekoratif bir öğe olarak kullanıldıkları düşüncesidir (Vorster, 1989, 284; Newby, 2005, 88-141). C. A. Salowey $(1995,80)$ antikçağda genç erkeklerin eğitiminde, Herakles'in bir güç sembolü olarak algılandığı ve bu nedenle Herakles Hermelerinin gymnasium'larla sıkı bir ilişki içerisinde olduğundan bahsetmektedir. Aynı şekilde E. B. Harrison $(1965,125)$ Herakles'in gymnasium'ların önemi için Hermes ile rekabet ettiğini ve Herakles Hermeleri ile gymnasium'lar arasında mantıklı bir bağ olduğundan söz etmektedir.

Bazı araştırmacılar Herakles'in Hermes ile birlikte gymnasium ya da palaestra'larda sporcuları koruyan bir tanrı olarak karşımıza çıktığını belirterek, Hermelerin bununla ilişkilendirilebileceğinden bahsetmektedirler (Wrede, 1985, 34-36; Vorster, 1989, 284; Miller, 2004, 50). Diğer bir düşünce ise Herakles'in himation gibi vücudu saran bir aslan postu giymesi ve dönemin filozof portrelerine benzer biçimde düşünceli, dalgın ve erdemli bir ifadeye sahip olmas1 nedeniyle, bu tipteki Herakles Hermelerinin insan ruhunun dayanıklılığını, bedensel dinginliğini ve asil bir düşünce yapısını simgelediği yönündedir (Vorster, 1989, 284-285; Işın, 2007, 94).

Antikçağda fiziki güç, dayanıklılık ve kahramanlığın kişileştirilmiş bir hali olan Herakles'in, gençlerin düşünsel ve bedensel olarak eğitim gördükleri yapılar için oldukça mantıklı ve önemli bir simge olduğu tartışılmaz bir gerçektir ve bu nedenle adı Gymnasium Tanrıları olarak Hermes ile beraber anılmaktadır (Pausanias, IV. 32. 1; Miller, 2004, 50). Ancak bu fikir, Herakles Hermelerinin steller ve lahitler üzerinde ne amaçla kullanıldığını, bu bağlamda Herakles'in mezar sanatı ya da ölüm ile olan ilişkisini açıklamaya yetmemekte hatta anlam karmaşasına neden olmaktadır. Aynı şekilde Herakles Hermelerinin Hellenistik Dönem filozof tiplemeleri (Smith, 2002, 35-39) ile ilişkilendirilmesi ve Herakles'in bu tipinin filozofik bir düşüncenin ürünü olarak yorumlanması, aynı tipte ancak çıplak olarak betimlenmiş olan Hermeler ile bir tezatlık oluşturmaktadır. Çünkü çıplak olarak, elinde bir bereket boynuzu ile betimlenmiş olan Herakles'i bir filozof ile karşılaştırmak pek olası değildir.

Aslında Herakles Hermelerinin anlamları ile ilgili yapılan yorumlamalarda ortaya çıkan en büyük sorun, var olan her bir tip için farklı bir anlamın var olduğunun düşünülmesidir. Bu sorun ile ilgili çözüm belki de, bugüne kadar farklı alanlarda ve tiplerde karşımıza çıkan tüm Herakles Hermelerini tek bir düşünce çatısı altında birleştirmek ve bu doğrultuda değerlendirmekle mümkündür. $\mathrm{Bu}$ bağlamda mezar sanatı ile ilişkili olarak betimlenen Herakles Hermelerinin kullanım amaçları konusundaki araştırmalar, konunun çözümünde oldukça yararlı bilgiler sunacaktır.

Mezar sanatı ile bağlantılı olarak üzerinde Herakles Hermesi bulunan toplam 6 mezar steli bulunmaktadır. Bu konu ile ilgili olarak dikkati çeken en önemli özellik Herakles Hermeli mezar stellerinin sadece Anadolu'nun batı bölümlerindeki kentlerde bulunmuş olmasıdır (Pfuhl, 1905, 79). Herakles Hermesi betimlemelerine sahip olan bu steller, erken örneklerdendirler ve bu durum Herakles'in koruyucu yönünün Batı Anadolu kentlerinde daha fazla benimsenmiş olabileceğini düşündürmektedir. Konu ile bağlantılı olarak Hermes Hermeleri de mezar stelleri üzerinde aynı şekilde Hellenistik Dönem ile birlikte görülmeye başlanmış ve genellikle Hermes Khthonios'un simgesi ya da gymnasium'lar için birer işaret levhası olarak yorumlanmışlardır (Pfuhl, 1905, 76-84; Harrison, 1965, 141; Pfuhl-Möbius, 1977, 46; Wrede, 1985, 44-48; Smith, 2002, 188-189, res. 219).

Genel olarak İ.Ö. II. yüzyıla tarihlendirilen söz konusu altı mezar stelinin dördü Smyrna'dan (Pfuhl- Möbius, 1977, no. 161, 256, 646, 730) (Res. 5, 7, 8, 9), biri Halikarnassos'tan (PfuhlMöbius, 1977, no. 141) (Res. 6) diğeri ise Myrina'dandır (Pfuhl-Möbius, 1977, no. 143). Örneklerde Herakles Hermeleri, genellikle stellerin sağ ya da sol kenarlarında ve yüksekçe bir 
podest üzerinde betimlenmişlerdir. $\mathrm{Bu}$ steller üzerinde yer alan Herakles Hermelerinin, insanların ölümsüzlük umudunun kutsal bir simgesi olduğu düşüncesinin (Farnell, 1921, 154) yanı sıra bedensel eğitim mekanlarına ait birer işaret levhası oldukları ve bununla bağlantılı olarak kahramansal bir anlam içerdikleri de düşünülmektedir (Pfuhl-Möbius, 1977, 46). Ancak bu steller üzerinde konu ile ilgili söz konusu fikirleri destekleyecek betimlemeleri bulmak ve bu doğrultuda yorumlamak oldukça zor gibidir ve söz konusu sahnelerin bedensel eğitimlerin verildiği bir mekanda geçtiği fikrinin, tekrar gözden geçirilmesinin gerekli olduğunu ortaya koymaktadır. Çünkü bu steller üzerinde yer alan figürlerin tümü giyiniktirler ve üzerlerine giydikleri tunik ve himation ile sporcudan çok olgun, entelektüel bir erkek görüntüsü içerisindedirler (Smith, 2002, 193) (Res. 5, 6, 8). Hermes Hermeli mezar stellerinde ise mekanın gymnasium ya da palaestra olduğunu belirtmek için figürler çoğunlukla himationlu ya da çıplak olarak betimlenmişlerdir (Pfuhl-Möbius, 1977, 46, no. 114, 126, 127, 131, 136, 138, 140).

Res. 7'de erkeklerle birlikte betimlenen kadın figürünün varlığ 1 ise bu sahnenin spor ile ilgili bir mekanda geçtiği fikrini tamamen engellemektedir. Antikçağda sporcu kadınların varlığı ve bu kadınlardan bazılarının Olympiyat oyunlarında başarı kazanarak, ön plana çıktıkları bilinmektedir (Ayrıntılı bilgi için bkz. Miller, 2004, 150-160). Ancak burada betimlenen kadın figürü, bir sporcu görüntüsü içerisinde değildir. Ayrıca Res. 6, 8 ve 9'da yer alan ağaçlar ve bu ağaçlar üzerinde yer alan yılan figürleri, sahnenin anlamını değiştirebilmektedir. Çünkü bu semboller ile gymnasium' lar arasında doğrudan bir anlam ilişkisi yoktur. Mezar stelleri üzerinde görülen ağaca sarılı yılan betimlemeleri, genellikle khthonik bir simge olarak yorumlanmaktadır (Pfuhl-Möbius, 1977, 46). Res. 9'daki alışılmadık kompozisyonu gymnasium'larla ilişkilendirmek ise mümkün değildir. Burada ana figürün elinde tuttuğu üzüm salkımı nedeniyle sahnenin, Herakles'in tarım ile ilgili bir kültü ile bağlantılı olduğu ileri sürülebilir (Ritter, 1995, 122-123. pl. 9, res. 8). Çünkü Herakles'in kırsal, tarımsal ve bağcilık ile ilgili de bir kültü bulunmaktadır. $\mathrm{Bu}$ kültte Herakles, kırsal alanlarda yaşayan ve tarım ile uğraşan halkın koruyucusu olarak tapınım görmüştür (Farnell, 1921, 151-153) ve elinde bereket boynuzu taşıyan Herakles Hermeleri bu koruyucu kült ile bağlantılı olabilir. Gymnasium ya da palaestra'larla ilişki kurmanın zor olduğu bu sahnelerde betimlenen Herakles Hermelerini, onun koruyucu yönü ile açıklamak belki de en güvenilir yoldur. Çünkü ana figürlerin hemen yanında, yüksekçe bir podest üzerinde betimlenerek ön plana çıarılan bu hermeler, ana figürler -dolayısıyla mezar sahibi- açısından mutlaka özel bir anlam ifade ediyor olmalıdırlar.

Herakles Hermeleri, mezar stellerinde olduğu gibi lahitler üzerinde de betimlenmişlerdir ve Hermeler genellikle lahitlerin kenarlarında yer almaktadır. Örnekler, Antalya Müzesi'ndeki bir Hippolytos Lahdi parçasında (Rogge, 1995, no. 48), (Res. 10), Delphoi Müzesi'nde korunan bir Meleager Lahdi'nde (Koch, 1975, no. 166), (Res. 11-12) ve Louvre Müzesi'nde bulunan Amazon Savaş1 konulu bir lahdin (Baratte-Metzger, 1985, no. 166) köşelerinde yer almaktadır (Res. 13). Antalya Müzesi'nde korunan lahit, kompozisyon ve figürler açısından Attika Hippolytos Lahitleri'ne birebir benzemektedir. Tek fark, alışılagelen köşe karyatidlerinin yerine burada bir Herakles Hermesinin kullanılmış olmasıdır (Rogge, 1995, no. 56, 59, 65). Meleager ve Amazon Savaşı konulu lahitlerde ise hermeler, grifonların yer aldığı arka yüzlerin, her iki köşesine betimlenmişlerdir. Grifonların yer aldığı benzer lahit örneklerinde, köşelerde genellikle boğa başı ya da sütunlar yer almaktadır (Bkz.: Rogge, 1995, no. 1, 19). Bazı lahit örneklerinde ise Herakles Hermeleri, birer girlant taşıyıcısı olarak görülmektedirler (Iş̧1, 2007, 96-97, kat. no. $28,52,58,71,78)$. Eros, boğa ya da koçbaşı gibi antikçağda en çok tercih edilen girland taşıyıcılarının yerine Herakles Hermelerinin tercih edilip kullanılması, konu açısından oldukça önemlidir (Res. 14). Söz konusu tüm lahit örneklerinde konu ile bağlantılı olarak dikkati çeken en büyük özellik adı geçen mitolojik konular ya da karışık yaratıklar ile Herakles arasında herhangi bir mitolojik bağlantının olmamasıdır ve belki de bu nedenle hermeler lahit köşelerine yerleştirilmişlerdir. Mitolojik konulardan bağımsız bir biçimde lahit köşelerine yerleştirilmiş 
olan Herakles Hermelerinin, mezar stellerinde olduğu gibi burada da mezar sahibi açısından özel koruyucu bir anlam ifade ettiğini ve bu düşüncenin bir sonucu olarak betimlendiklerini söylemek olasıdır.

Mezar sanatı ile ilgili olarak mezar içerisinde kullanılmış pişmiş toprak Herme örnekleri de bulunmaktadır (Res. 15). Pişmiş topraktan yapılmış küçük boyutlu örnekler özellikle İ.Ö. I. yüzyılda Mylasa, Pergamon gibi Anadolu kentlerinin yanı sıra Delos ve Güney Rusya gibi oldukça geniş bir coğrafyada yaygın olarak kullanılmışlardır (Örnekler için bkz.: LIMC IV 1, 1156-1160; Töpperwein, 1976, 130, no. 533; Çakıc1, 2007, 86, Res. 8; Işın, 2007, kat no. 56, res. 61; Marcade, 1969, 454-456, lev. XIX, XX). Pek çok araştırmacı, mezar içerisindeki pişmiş topraktan yapılmış bu tür Hermelerin, bir sporcu simgesi olarak mezar sahibinin atlet kimliğini vurgulamak amacıyla kullanıldığını düşünmektedir (Wrede, 1985, 42-44). Herakles Hermelerinin koruyucu bir anlam içerdiğinin en önemli kanıtı belki de bu tür örneklerde bulunmaktadır. Çünkü bu hermeler, antikçağda insanların bedenlerini ve ruhlarını kötülüklere karşı korumanın en çok gerekli olduğunu düşündükleri bir yer olan mezar yapıları içerisinde kullanılmışlardır. Böylece bu hermeler, atlet kimliğini vurgulamaktan çok mezar içerisinde yatan ölünün ruhunu ve huzurunu kötülüklere karşı koruyan apotropaik bir simge olarak yorumlamanın oldukça uygun ve mantıklı olduğunu güçlü bir biçimde düşündürmektedir.

Hellenistik Dönem ile başlayıp Roma Dönemi sonlarına kadar mezar sanatında görülen Herakles Hermelerinin ne amaçla kullanılmış olabileceği sorusunun yanıtını, Herakles'in kahraman ve koruyucu kişiliğinde aramak, belki de en güvenilir yoldur. Çünkü antikçağda Herakles, fiziki gücün yanı sıra kötülükleri yok eden, sözünde durmayanları cezalandıran, insanın başına gelen afet ve belaları alt edip onları engelleyen, yiğitliğin ve yürekliliğin de simgesidir. Herakles'in zorlu 12 görevinden bazıları şüphesiz insanlığın yararı içindir (Erhat, 2000, 137-140). Bu koruyucu/kurtarıcı yönüyle Herakles, zaman içerisinde hem kahraman hem de tanrı olarak pek çok kentte, farklı epithetler altında tapınım görmüştür. Erken dönem yazıtları ışı ğında Herakles, kallinikos (zafer kazanmış, muzaffer), soter (kurtarıc1) ve aniketos (yenilmez) gibi epithetler ile savaşların, atletlerin ve yarışların koruyucusudur (Farnell, 1921, 146-154). Daha sonraki dönemlerde ise Herakles'in, savaş ve spor ile ilgili bu tanrısallığının yerine, insanların yaşamları boyunca karşılarına çıkan tehlikelerden, kötü ruhlardan ve hastalıklardan korunma eğilimleri nedeniyle bu koruyucu yönünü benimsedikleri görülmektedir. Bazı Hellen konut kapılarının üzerinde yer alan ve "Adil zaferin Herakles'i burada yaşıyor, hiçbir kötülük giremez" yazıs1, Herakles'in bu koruyucu yönünü açıkça belgelemektedir (Farnell, 1921, 148). $\mathrm{Bu}$ bağlamda aleksikakos ve apotropaios epithetleri de oldukça önemlidirler. Çünkü bu epithetler ile Herakles, kötülükleri yok eden, engelleyen bir özelliğe sahiptir (Mouratidis, 1985, 230). Araştırmacılar herme şeklindeki bazı Herakles betimlemelerini aleksikakos epitheti ile ilişkilendirmektedirler, buna en iyi örnek Ludovisi Hermesi olarak adlandırılan Herakles heykelidir (Bu konu ile ilgili olarak bkz. Frickenhaus, 1911, 31-33; Heintze, 1965; Woodford, 1976). Bazı araştırmacılar ise her iki epithetin de Herakles'in iyileştiren, şifa veren bir özelliği ile bağlantılı olduğunu belirtmektedirler (Levy, 1934, 42; Salowey, 1995, 165-170) ve Farnell $(1921,149)$ apotropaios epitheti ile ilgili açıklamasında, filozof Philostratos'un aktarımlarından yararlanarak, Ephesos'da vebaya neden olan bir kötülüğün yok edilmesi ile ilgili bir bilgi vermektedir. Ayrıca Geç Phryg stellerinde Kerberos ile birlikte görülen Herakles'in ölümü yenen koruyucu bir tanrı olarak yorumlanması (Pfuhl- Möbius, 1977, 499); aynı şekilde Thasos'da şehir kapıları ve geçitlerin koruyucu tanrısı olarak da tapınım görmüş olması (Bonnefoy, 1992, 184) konu ile bağlantılı olarak önemlidir. Bu düşüncelere paralel olarak Ephesos'ta Kuretler Caddesi'nin başlangıcında yer alan ve Herakles Hermesi betimlemesine sahip iki sütundan oluşan kapı, benzer bir koruyucu düşüncenin ürünü olabilir (Bammer, 1988, res. 30).

Herakles'in bu koruyucu özelliği göz önüne alındığında, gymnasium'lar için bir simge ya da 
dekorasyon öğesi olarak tanımlanan Herakles Hermelerinin, aslında farklı bir anlama sahip olabileceği fikri güçlenmektedir. Çünkü insanlar, zaman içerisinde Herakles’i tanrılaştırmış, onları kötülüklerden ve belalardan koruduğuna inanmışlardır. Bu nedenle mezar konteksi içerisinde kullanılmış olan tüm Herakles Hermelerini, mezar içerisinde yatan ölünün ruhunu ve huzurunu kötülüklere karşı koruyan apotropaik bir simge olarak yorumlamak; aynı şekilde gymnasium gibi bedensel eğitim alanlarında ele geçen Herakles Hermelerini atletlere ve sporculara sağlık ve başarı sağlayan bir koruyucu olarak açıklamak mümkündür. Herakles'in bu koruyucu ya da kötülükleri engelleyici tanrısal yönüyle, hem mezar sanatında hem de gymnasium, agora ve hamam gibi tüm insanların kullanımına açık olan alanlarda karşımıza çıkan Herakles Hermelerinin, kullanım amacı ve anlam bütünlüğü mantıklı bir biçimde sağlanmış olmaktadır. Aynı düşünce doğrultusunda aleksikakos, apotropaios ya da soter gibi epithetler ile koruyucu tanrı olarak tapınım gören Herakles'in herme biçimindeki bu görüntüsünün, bir kült yontusu olarak algılandığını düşünmek ise olasıdır. Böylece ister halka açık bir yapıda, isterse mezar sanatı ile ilgili bir alanda ele geçmiş olsun, antikçağda insanların Herakles'i mitolojik bir kahraman olarak görmelerinin yanı sıra, bir kurtarıcı/koruyucu olarak da gördükleri unutulmamalı, ele geçen Herakles Hermelerinin anlamları ve kullanım amaçları açıklanmaya çalışılırken, bu önemli ipucu göz ardı edilmemelidir.

\section{KAYNAKÇA}

Bammer, A. (1988). Ephesos. Stadt an Fluß und Meer. Graz.

Baratte, F. \& Metzger, C. (1985). Musée du Louvre, Sapkophages en pierre d'époques romaine et paléochretienne. Paris.

Bonnefoy, Y. (1992). Greek and Egyptian Mythologies. Chicago.

Çakıcı, M. (2007). "Milas İsmetpaşa Mahallesi 284 Ada 23-3 Parsellerde Kurtarma Kazısı”. Müze Kurtarma Kazıları Sonuçları, 15, 83-94.

Curtius, L. Die Antike Herme: eine mythologisch-kunstgeschichtliche Studie (1903). Munich.

Cicero, M. Tullius, Letters to Atticus. Trans. E. S. Shuckburgh (1908). London, New York: Loeb.

Erhat, A. (2000). Mitoloji Sözlüğü. İstanbul.

Farnell, L. R. (1921). Greek Hero Cults and Ideas of Immortality. Oxford.

Frickenhaus, A. (1911). "Hageladas". Jahrbuch des Deutschen Archäologischen Instituts, 26, 24-34.

Goldman, H. (1942). "The Origin of the Greek Herm". American Journal of Archaeology, 46, 58-68.

Harrison, E. B. (1965). "Archaic and Archaistic Sculpture. Agora XI". The American School of Classical Studies at Athens.

Harrison, J. E. (1912). "Themis": A Study of the Social Origins of Greek Religion. Cambridge.

Heintze, von H. (1965). "Herakles Alexikakos". Mitteilungen des Deutschen Archäeologischen Instituts Römische Abteilung, 72, 14-40.

Iş1k, F. (2007). Girlanden- Sarkophage aus Aphrodisias. Sarkophag-Studien 5. Mainz.

Işın, G. (2007). Patara Terrakottaları. Hellenistik ve Erken Roma Dönemleri, Patara V. 1. İzmir.

Koch, G. (1975). Die Mythologischen Sarkophage: Meleager. Die antiken Sarkophagreliefs XII 6. Berlin.

Kreikenbom, D. (1990). Bildwerke Nach Polyklet. Kopienkritische Untersuchungen zu den männlichen statuarischen Typen nach polykletischen Vorbildern. Berlin.

LIMC Lexicon Iconographicum Mythologiae Classicae IV I. Artemis Verlag Zürich und München. 1988.

Levy, G. R. (1934). "The Oriental Origin of Herakles". The Journal of Hellenic Studies, 54, 40-53.

Lullies, R. (1931). Die Typen der griechischen Hermen. Königsberg.

Marcadé, J. (1969). Au Musée de Délos: étude sur la sculpture hellénistique en ronde bosse découverte dans l'île. Paris.

Mendel, G. (1908). Musées Impériaux Ottomans. Catalogue des figurines grecques de terre cuite. İstanbul. 
Miller, S. G. (2004). Ancient Greek Athletics. Italy.

Mouratidis, J. (1985). "The Origin Of Nudity in Greek Athletics". Journal of Sport History, 12, 213-232. Newby, Z. (2005). Greek Athletics in the Roman World: Victory and Virtue. Oxford.

Pausanias, Guide to Greece Volume 2: Southern Greece. Trans. P. Levi, (1971). London, New York: Loeb.

Pfuhl, E. (1905). "Das Beiwerk auf den ostgriechischen Grabreliefs". Jahrbuch des Deutschen Archäologischen Instituts, 20, 123-155.

Pfuhl, E., \& Möbius, H. (1977). Die ostgriechischen Grabreliefs. Mainz.

RE Paulys Realencyclopädie der Classischen Altertumswissenschaft. Stuttgart, 1912.

Ritter, S. (1995). Hercules in der Römischen Kunst von der Anfängen bis Augustus. Archäologie und Geschichte 5. Heidelberg.

Rogge, S. (1995). Die Attischen Sarkophage: Achill und Hippolytos. Die antiken Sarkophagreliefs IX 1. Berlin.

Salowey, C. A. (1995). The Peloponnesian Herakles: Cult and Labor. Bryn Mawr College.

Smith, R. R. R. (1991). Hellenistic Sculpture. London.

Töpperwein, E. (1976). Terrakotten von Pergamon. Pergamenische Forschungen 3. Berlin.

Volster, C. (1988). "Die herme des Fellbekleideten Herakles Typenwandel und Typenwanderung in Hellenistischer und Römischer Zeit”. Köln Jahrbuch, 21, 7-34.

Vorster, C. (1989). Bonner Abguß einer verschollenen Heraklesherme. Ed. H. U. Cain, H.Gabelmann, \& D. Salzmann. Festschrift für Nikolaus Himmelmann, Beiträge zur Ikonographie und Hermeneutik, 281-7. Mainz

Willer, F. (1994). Zur Herstellungstechnik der Herme. Ed. G. H. Salies, H. von Prittwitz, Gaffron, \& G. Bauchhenß. Das Wrack. Der antike Schiffsfund von Mahdia, 959-970. Köln.

Woodford, S. (1976). "Heracles Alexikakos Reviewed". American Journal of Archaeology, 80, 291-294.

Wrede, H. (1985). Die Antike Herme. Mainz.

\section{Resimler Listesi}

Res. 1 Volster, 1988, abb. 1.

Res. 2 LIMC, IV 1, 1168.

Res. 3 Ritter 1995, pl. 9, fig. 8.

Res. 4 LIMC, IV 1, 1254.

Res. 5 Pfuhl-Möbius, 1977, no. 161.

Res. 6 Pfuhl-Möbius, 1977, no. 141.

Res. 7 Pfuhl-Möbius, 1977, no. 646.

Res. 8 Pfuhl-Möbius, 1977, no. 256.

Res. 9 Pfuhl-Möbius, 1977, no. 730.

Res. $10 \quad$ Rogge, 1995, no. 48.

Res. $11 \quad$ Koch, 1975, no. 140.

Res. 12 LIMC, IV 1, 1118.

Res. 13 Baratte-Metzger, 1985, no. 166.

Res. 14 Işık, 2007, Kat. 28f, taf. 28-8.

Res. 15 Çakıcı, 2007, fig. 8. 


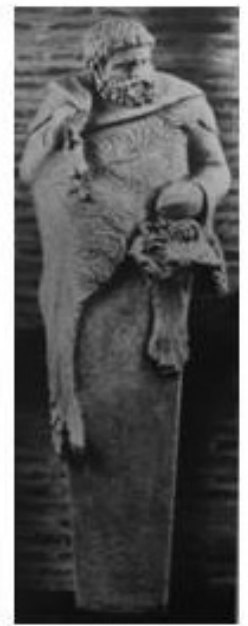

Res. 1

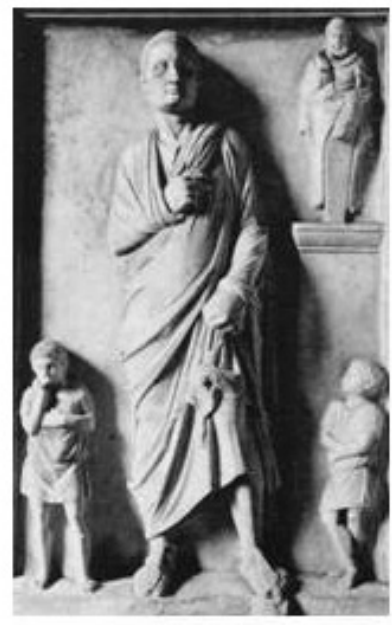

Res. 5

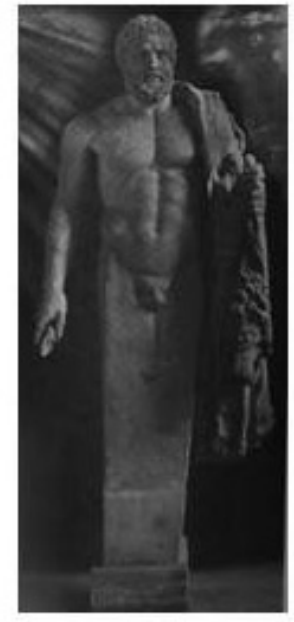

Res. 2

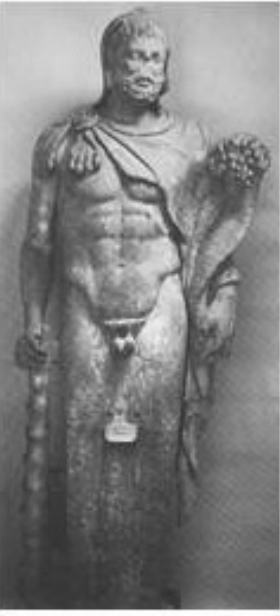

Res. 3

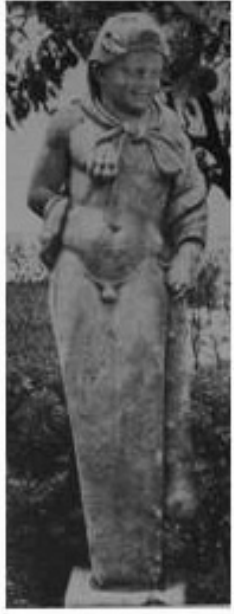

Res. 4

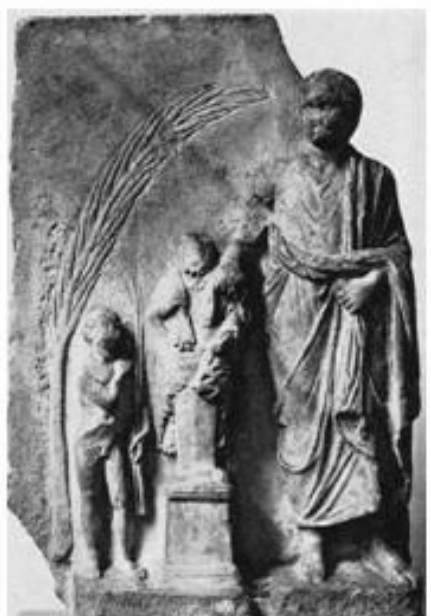

Res. 6

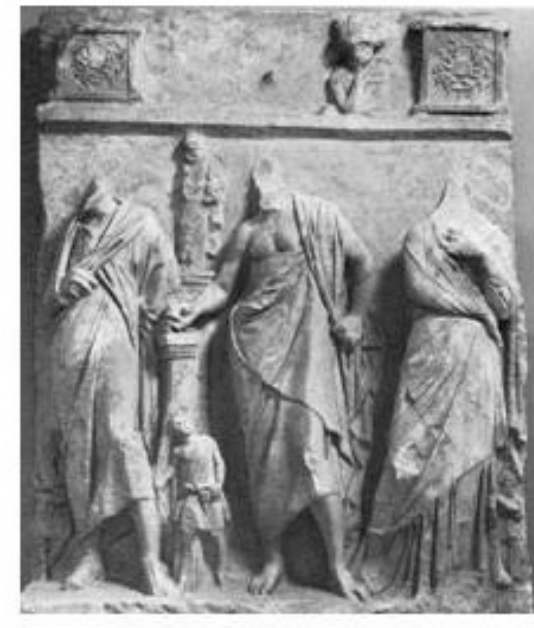

Res. 7

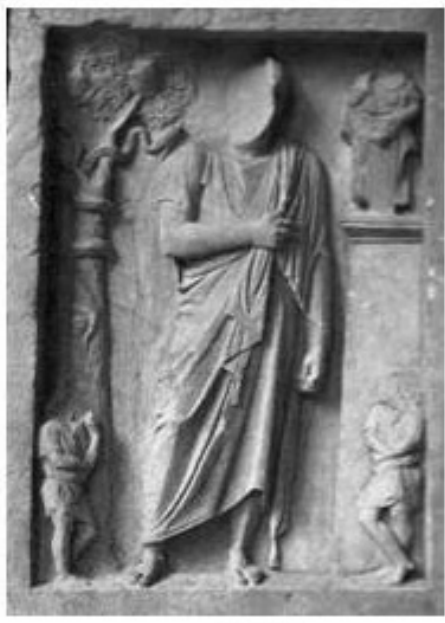

Res. 8

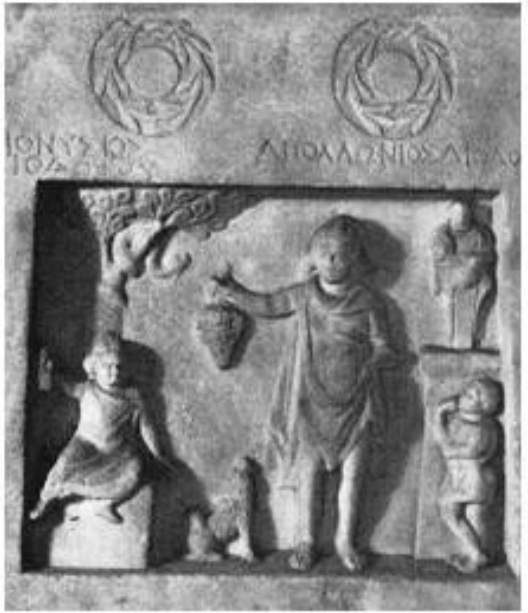

Res. 9 


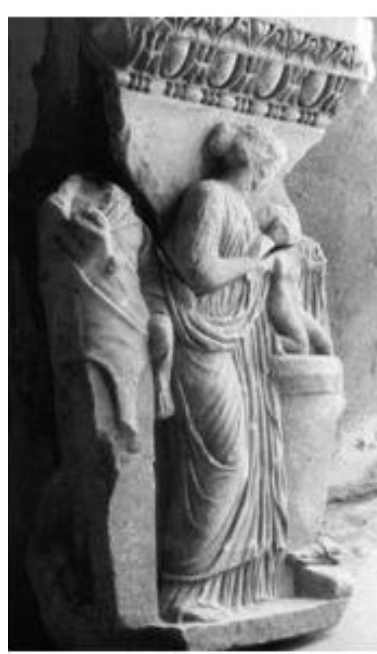

Res. 10

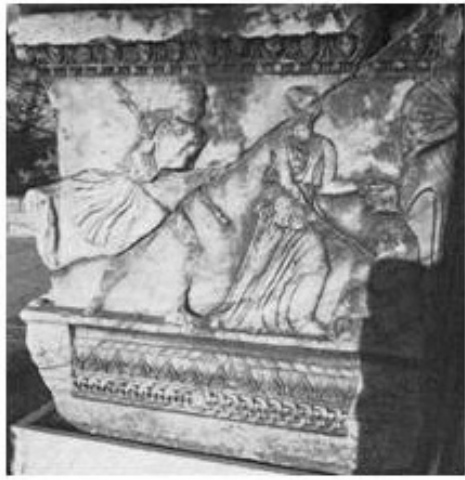

Res. 11

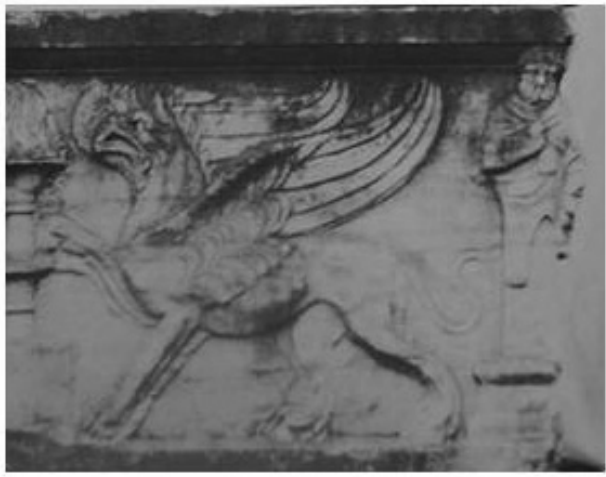

Res. 12

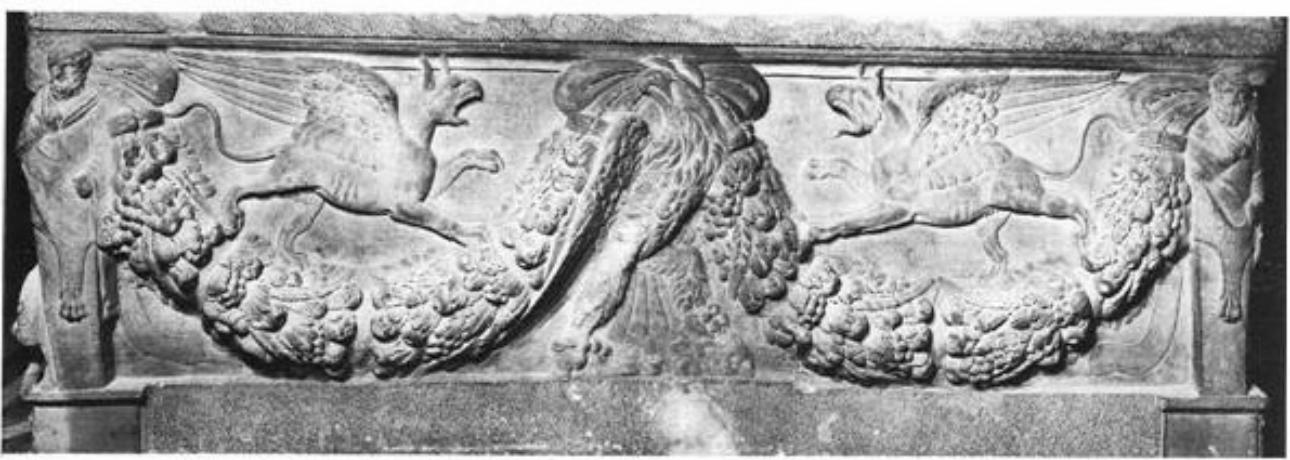

Res. 13

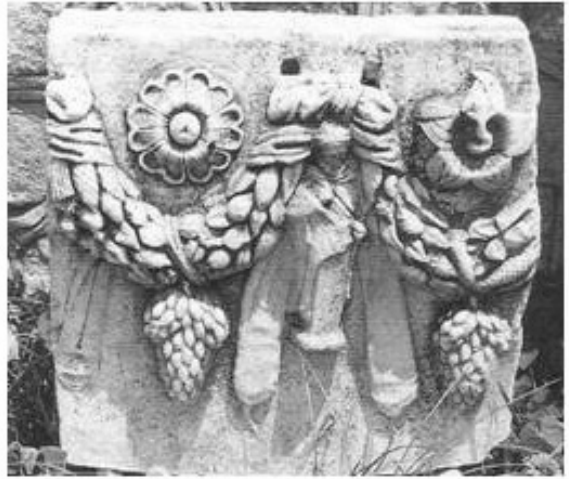

Res. 14

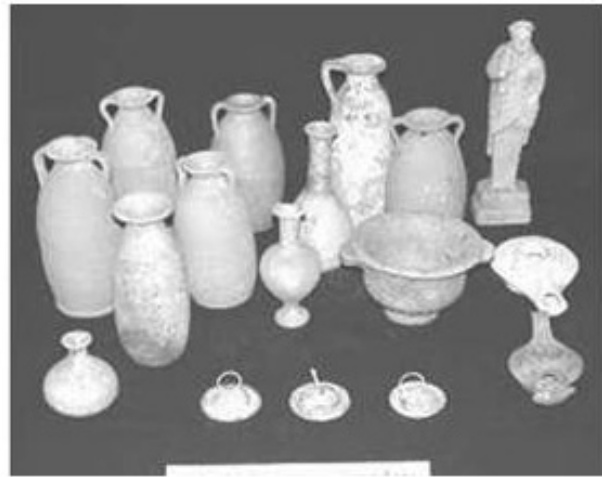

Res. 15 
